\title{
De rol van de Processability Theory van Pienemann in de verwerving van het Nederlands als tweede taal bij Poolse studenten
}

\begin{abstract}
Pienemann's Processability Theory (PT) hypothesizes that the grammatical structures of a second language are acquired in an order that is universal for all languages. The main aim of this article is to investigate the validity and reliability of this theory for the acquisition process of Dutch as L2 by Polish students. PT was tested on a group of 15 first-year Dutch philology students at the University of Wrocław, after 300 hours of intensive Dutch language course. The oral production test checked the acquisition level of three Dutch grammatical structures, representing consecutive stages of L2-development: agreement between adjective and noun (stage III), agreement between verb and subject (stage IV) and word order in subordinate clauses (stage V). Pienemann's hypothesis seems to be valid for the acquisition of Dutch language as L2 only if the criterion of one correct use of a grammatical structure is taken into consideration. When it comes to the two other criteria $(50 \%$ and $90 \%$ of correct use) the structure representing stage III seems to be acquired after the structures representing stages IV and V, which forms a counter-evidence for the Processability Theory.
\end{abstract}

Keywords: second-language acquisition, Processability Theory, Pienemann, Dutch as L2, universal acquisition order

\section{Inleiding}

Didactiek van vreemde talen en tweede-taalverwerving behoren tot de meest ontwikkelde disciplines van de taalkunde. Binnen deze vakgebieden blijkt de Processability Theory (hierna PT) van Pienemann (1998) een interessante en discussie wekkende benadering te zijn. De theorie beschrijft de verwervingsvolgorde van de grammaticale structuren van een tweede taal. Uit de literatuurstudie is gebleken dat PT als theoretische basis diende voor publicaties met betrekking tot verschillende talen. De meeste ervan, zoals het onderzoek naar het Duits (Baten 2011), Zweeds, Noors en Deens (Glahn e.a. 2001), Spaans (Bonilla 2012), Italiaans (Di Biase 2007) of Japans (Di Biase en Kawaguchi 2002) hebben de hypothese van 
Pienemann volledig bevestigd. Sommige onderzoeken, zoals dat naar het Engels (Dyson 2009), hebben de validiteit van PT slechts gedeeltelijk bevestigd. Andere publicaties, zoals bijvoorbeeld die over het Arabisch (Alhawary 2003), lijken Pienemanns model volledig te ontkrachten. Ook voor de Nederlandse taal is zo'n publicatie verschenen. Uit het onderzoek van Arends (2007) blijkt dat PT niet helemaal opgaat voor het Nederlands als T2.

Dit artikel heeft als doel om de Processability Theory te toetsen aan het verwervingsproces van het Nederlands als tweede taal bij Poolse studenten. Hiervoor wordt een beroep gedaan op het eerder vermelde onderzoek van Arends.

\section{Processability Theory}

Pienemann veronderstelt dat het proces van T2-verwerving in een aantal vaste stadia verloopt (zgn. verwerkingsprocedures). Deze procedures zijn onlosmakelijk verbonden met de morfologische en syntactische verschijnselen van een tweede taal. Met behulp van dit model zou de volgorde van de procedures kunnen worden voorspeld die universeel is voor alle talen.

Pienemanns universele volgorde van T2-verwerving bestaat uit onderstaande opeenvolgende stadia (Pienemann 2005):

1. Losse woorden

2. Lexicale en grammaticale categorieën

3. Syntactische categorieën

4. Hoofdzinnen

5. Bijzinnen.

Het proces van T2-verwerving begint met het verwerken van losse woorden, die nog geen grammaticale informatie bevatten. In het tweede stadium komt het herkennen van woordsoorten en het toekennen van grammaticale kenmerken aan deze woordsoorten, bijvoorbeeld het getal van een substantief. Tijdens de volgende stap van het proces gaat men zinsdelen construeren. Hier gaat het om het uitwisselen van informatie binnen zinsdelen, zoals in het geval van adjectief-substantief congruentie. In het vierde stadium wordt informatie-uitwisseling tussen zinsdelen mogelijk, zoals bij subject-persoonsvorm congruentie. In de laatste fase wordt er een onderscheid gemaakt tussen de woordvolgorde in de hoofd- en bijzin (Arends 2007: 80).

De ontwikkeling van de boven genoemde stadia heeft een incrementeel en hiërarchisch karakter, dat wil zeggen dat "de procedures elkaar noodzakelijk opvolgen, waarbij toepassing van de eerdere procedures een voorwaarde is voor het kunnen toepassen van een volgende procedure" (Arends 2007: 79). Volgens Pienemann is de volgorde van de stadia van de ontwikkeling van een tweede taal onafhankelijk van de moedertaal van de T2-leerder en is ze gebaseerd op de structuur en de grammaticale regels van de T2 (Pienemann 2005). 


\section{Onderzoek}

Arends heeft de verwervingsvolgorde van drie Nederlandse taalstructuren onderzocht die bij opeenvolgende stadia van het verweringsproces horen: adjectief-substantief congruentie, subject persoonsvorm congruentie en de volgorde in de bijzin. Aan haar onderzoek hebben 32 deelnemers met verschillende moedertalen deelgenomen die 60 uur taalverwerving achter de rug hadden. Ze hebben een productietest gedaan waaruit bleek dat subject-persoonsvorm congruentie eerder verworven wordt dan adjectief-substantief congruentie wat niet in overeenstemming is met het PT model.

In dit onderzoek worden een paar aspecten van het idee van Pienemann geanalyseerd met betrekking tot het verwervingsproces van de Nederlandse taal als T2 bij Poolse studenten. Om dit doel te bereiken zijn drie taalverschijnselen uitgekozen die eerder ook door Arends werden onderzocht, namelijk:

- congruentie tussen een attributief gebruikt adjectief en het bijbehorende substantief (stadium III); hier gaat het om de uitgang -e die adjectieven krijgen als ze niet voor onbepaalde het-woorden in het enkelvoud staan

bijv. een blauwe fiets, een rood $\underline{\varnothing}$ huis;

- congruentie tussen het subject en de persoonsvorm (stadium IV); hier gaat het om de uitgang -t voor de derde persoon enkelvoud of -en voor de derde persoon meervoud

bijv. De vrouw doet boodschappen. De vrouwen doen boodschappen.;

- de plaatsing van werkwoorden in de bijzin (stadium V), achteraan in de zin bijv. Ik denk dat de vrouw boodschappen doet (Arends 2007: 82).

Op basis van de door Pienemann voorgestelde hypothese zouden we dus kunnen vermoeden dat de adjectief-substantief congruentie (A) die bij stadium III hoort, eerder verworven wordt dan de subject-persoonsvorm congruentie (B) die betrekking heeft op stadium IV, die op haar beurt eerder verworven wordt dan de plaatsing van werkwoorden in de bijzin (C). Indien we echter rekening houden met de resultaten van het onderzoek van Arends, verwachten we een andere verwervingsvolgorde dan gewoon "A voor B voor C".

\section{Productietest}

Aan het onderzoek hebben 15 proefpersonen deelgenomen - 3 mannen en 12 vrouwen. Deze deelnemers waren allen eerstejaars studenten neerlandistiek aan de Universiteit van Wrocław, die op het moment van het onderzoek ongeveer 300 uur taalverwervingscolleges achter de rug hadden. De gemiddelde leeftijd van de deelnemers is 20,3 jaar (19-24 jaar).

Alle studenten hebben een mondelinge productietest gedaan, net zoals bij Arends (2007: 83). De test bestond uit drie delen met in totaal 30 plaatjes. Bij ieder deel kregen de deelnemers via een Powerpointpresentatie tien plaatjes te zien en een vraag te beantwoorden. 
In het eerste deel van het onderzoek kregen de studenten tien voorwerpen in verschillende kleuren te zien en moesten ze een antwoord geven op de vraag Wat is dat?. De bedoeling was om de juiste vorm van het adjectief te gebruiken, bijvoorbeeld een groene fiets in plaats van een groen fiets of een geel huis in plaats van een gele huis. In het tweede deel kregen de deelnemers tien plaatjes te zien van mensen die een bepaalde handeling uitvoeren. De taak van de deelnemers was om de vraag Wat doet deze persoon/Wat doen deze personen? te beantwoorden. In dit geval moesten ze rekening houden met de juiste uitgang van de persoonsvorm, bijvoorbeeld Het meisje maakt haar huiswerk in plaats van het meisje maken haar huiswerk.

Ten slotte kregen de studenten tien andere plaatjes te zien die bepaalde handelingen uitbeeldden. Tijdens dit onderdeel van de test moesten ze een antwoord geven op de vraag Wat denk je dat deze persoon doet/deze personen doen?. De bedoeling was dat ze de persoonsvorm en alle andere werkwoorden op de tweede positie zouden plaatsen. De deelnemers werden gevraagd om zo precies mogelijk iedere vraag te beantwoorden, dat wil zeggen met een volledige zin. Indien nodig, werd soms een extra vraag gesteld, bijvoorbeeld wanneer een antwoord wel grammaticaal correct was, maar niet compleet.

Ik: Wat denk je dat deze persoon doet?

Proefpersoon: Hij doet boodschappen.

Ik: Maar wat denk je dat deze persoon doet?

Proefpersoon: Ik denk dat hij boodschappen doet.

Alle antwoorden van de studenten werden opgeslagen en op basis van deze resultaten werden aan iedere uiting punten toegekend.

\section{Verwervingscriterium}

Een van de belangrijkste maar ook het meest controversiële punten bij de analyse van de verzamelde data is het verwervingscriterium. Met andere woorden: wanneer kun je een bepaalde taalstructuur als verworven beschouwen? Voor dit onderzoek zijn drie verschillende verwervingscriteria opgesteld:

- een correct gebruik van de structuur, zgn. emergence criterion (Pienemann 1998),

-50 procent correct gebruik,

- 90 procent correct gebruik (Brown 1973).

Net zoals in het onderzoek van Arends, kan men voor iedere uiting 1 punt krijgen als die correct wordt gevormd of 0 punten als die incorrect wordt gevormd (Arends 2007: 85). Bij adjectief-substantief congruentie gaat het echter alleen om de juiste uitgang van het adjectief. In de praktijk betekent dat bijvoorbeeld dat 1 punt wordt toegekend aan antwoorden zoals twee rode stoels, maar niet aan antwoorden zoals een rood stoel of gewoon een stoel. Bij subject-persoonsvorm con- 
gruentie wordt alleen gekeken naar de juiste uitgang van de persoonsvorm (-t voor $3^{\mathrm{e}}$ persoon enkelvoud en -en voor $3^{\mathrm{e}}$ persoon meervoud). Daarom kregen de studenten punten voor uitingen als Het meisje maakt boodschappen in plaats van Het meisje doet boodschappen. Bij de volgorde in de bijzin gaat het alleen om de juiste positie van werkwoorden (achteraan) en niet om congruentie tussen het subject en de persoonsvorm. In dit geval wordt 1 punt toegekend aan uitingen als Ik denk dat de vrouw boodschappen doen maar Ik denk dat de vrouw doet boodschappen kreeg 0 punten. Vervolgens heb ik de punten opgeteld en berekend hoeveel procent van de antwoorden correct gevormd was. Op deze percentages werden de drie eerder genoemde verwervingscriteria toegepast.

\section{Verschillen en overeenkomsten met de benadering van Arends}

Voor mijn onderzoek heb ik dezelfde Nederlandse taalverschijnselen uitgekozen als Arends; minstens twee van de drie geanalyseerde taalaspecten - adjectief-substantief congruentie en woordvolgorde in de bijzin - leveren veel problemen op voor Poolstalige studenten die Nederlands als tweede taal leren. De deelnemers hebben in dit experiment ook een mondelinge productietest gedaan met soortgelijke opdrachten als die van Arends. Bovendien heb ik dezelfde formule van puntentoekenning toegepast.

Het basisverschil tussen dit onderzoek en dat van Arends is het soort van T2-verwerving: de deelnemers van Arends leren Nederlands in een Nederlandstalige omgeving. De deelnemers in dit experiment leren Nederlands in een Poolstalig omgeving, en dus als vreemde taal. In de praktijk betekent het dat ze tijdens het taalverwervingscollege ook wat input in het Pools krijgen. Bovendien hebben we bij Arends te maken met verschillende moedertalen van deelnemers en in mijn onderzoek is Pools de moedertaal van alle deelnemers.

Een van de meest relevante verschillen zijn de verwervingscriteria. Arends heeft gekozen voor 30 procent, 50 procent en 80 procent correct gebruik van een grammaticale structuur. Ik heb daarentegen gekozen voor het criterium voorgesteld door Pienemann (eenmalig correct gebruik), het criterium van 50 procent correct gebruik en het criterium van Brown ( 90 procent correct gebruik). De reden hiervoor is om de verschillen in de resultaten qua verwerkingscriterium wat sterker en duidelijker te maken. Het eerste en het derde criterium impliceren namelijk twee volledig tegenovergestelde benaderingen en ze laten twee verschillende perspectieven zien: is eenmalig systematisch correct gebruik van een grammaticale structuur genoeg om vast te stellen dat de structuur wordt verworven of moeten eigenlijk bijna alle gevallen van het gebruik van deze structuur correct zijn?

Een ander verschil dat van redelijk groot belang is in dit onderzoek, is de hoeveelheid en soort van instructies die de deelnemers krijgen. Arends heeft een 
soort afleidingsmanoeuvre toegepast ("De studenten is verteld dat het ging om het juiste gebruik van de kleuren") en heeft misschien te veel sturing gebruikt ("De studenten is $(\ldots)$ verteld $(\ldots)$ dat ze hun antwoord moesten beginnen met: 'Ik denk dat..."'2). Mijn bedoeling was om de hoeveelheid van de instructie en sturing zo veel mogelijk te beperken zodat de uitingen van de studenten zo spontaan mogelijk zouden zijn.

\section{Resultaten en conclusies}

In de onderstaande tabel zijn de resultaten van alle deelnemers per testonderdeel opgenomen. Een vinkje in de eerste drie kolommen betekent dat de gegeven structuur minstens één keer correct is gevormd door de proefpersoon. In de volgende drie kolommen wil een vinkje zeggen dat de structuur in minstens 50 procent van de gevallen ( 5 keer) correct is gevormd. Een vinkje in de laatste drie kolommen betekent dat de gegeven structuur in minstens 90 procent van de gevallen $(9 \mathrm{keer})$ correct is gevormd door de proefpersoon.

Tabel 1. Individuele resultaten van de productietest per onderdeel en verwervingscriterium

\begin{tabular}{|l|c|c|c|c|c|c|c|c|c|}
\hline & \multicolumn{3}{|c|}{1 correct gebruik } & \multicolumn{3}{c|}{$50 \%$ correct } & \multicolumn{3}{c|}{$90 \%$ correct } \\
\hline $\begin{array}{l}\text { Proef-per- } \\
\text { Soon }\end{array}$ & $\begin{array}{c}\text { ADJ- } \\
\text {-SUB }\end{array}$ & $\begin{array}{c}\text { SUB- } \\
\text {-PV }\end{array}$ & $\begin{array}{c}\text { BI- } \\
\text {-JZIN }\end{array}$ & $\begin{array}{c}\text { ADJ- } \\
\text {-SUB }\end{array}$ & $\begin{array}{c}\text { SUB- } \\
\text {-PV }\end{array}$ & $\begin{array}{c}\text { BI- } \\
\text {-JZIN }\end{array}$ & $\begin{array}{c}\text { ADJ- } \\
\text {-SUB }\end{array}$ & $\begin{array}{c}\text { SUB- } \\
\text {-PV }\end{array}$ & $\begin{array}{c}\text { BI- } \\
\text {-JZIN }\end{array}$ \\
\hline M_20(1) & $\checkmark$ & $\checkmark$ & - & $\checkmark$ & $\checkmark$ & - & - & $\checkmark$ & - \\
\hline V_19(1) & $\checkmark$ & $\checkmark$ & $\checkmark$ & $\checkmark$ & $\checkmark$ & $\checkmark$ & - & $\checkmark$ & - \\
\hline V_23 & $\checkmark$ & $\checkmark$ & - & $\checkmark$ & $\checkmark$ & - & - & $\checkmark$ & - \\
\hline V_21 & $\checkmark$ & $\checkmark$ & - & $\checkmark$ & $\checkmark$ & - & - & $\checkmark$ & - \\
\hline V_19(2) & $\checkmark$ & $\checkmark$ & - & $\checkmark$ & $\checkmark$ & - & - & $\checkmark$ & - \\
\hline V_20(1) & $\checkmark$ & $\checkmark$ & $\checkmark$ & $\checkmark$ & $\checkmark$ & $\checkmark$ & $\checkmark$ & $\checkmark$ & $\checkmark$ \\
\hline V_19(3) & $\checkmark$ & $\checkmark$ & $\checkmark$ & $\checkmark$ & $\checkmark$ & $\checkmark$ & - & - & $\checkmark$ \\
\hline V_24 & $\checkmark$ & $\checkmark$ & $\checkmark$ & $\checkmark$ & $\checkmark$ & $\checkmark$ & - & $\checkmark$ & - \\
\hline M_22 & $\checkmark$ & $\checkmark$ & $\checkmark$ & $\checkmark$ & $\checkmark$ & $\checkmark$ & - & $\checkmark$ & - \\
\hline V_19(4) & $\checkmark$ & $\checkmark$ & $\checkmark$ & $\checkmark$ & $\checkmark$ & $\checkmark$ & - & $\checkmark$ & - \\
\hline M_20(2) & $\checkmark$ & $\checkmark$ & $\checkmark$ & $\checkmark$ & $\checkmark$ & $\checkmark$ & $\checkmark$ & $\checkmark$ & $\checkmark$ \\
\hline V_20(2) & $\checkmark$ & $\checkmark$ & $\checkmark$ & $\checkmark$ & - & $\checkmark$ & - & - & - \\
\hline V_20(3) & $\checkmark$ & $\checkmark$ & $\checkmark$ & $\checkmark$ & $\checkmark$ & $\checkmark$ & $\checkmark$ & $\checkmark$ & $\checkmark$ \\
\hline V_19(5) & $\checkmark$ & $\checkmark$ & $\checkmark$ & $\checkmark$ & $\checkmark$ & $\checkmark$ & - & $\checkmark$ & - \\
\hline V_19(6) & $\checkmark$ & $\checkmark$ & $\checkmark$ & $\checkmark$ & $\checkmark$ & $\checkmark$ & - & $\checkmark$ & - \\
\hline
\end{tabular}

M - man; V - vrouw; ADJ-SUB - adjectief-substantief congruentie; SUB-PV - substantiefpersoonsvorm congruentie; BIJZIN - woordvolgorde in de bijzin

\footnotetext{
${ }^{1}$ Arends 2007: 83 .

2 Arends 2007: 84.
} 
Als we uitgaan van het verwervingscriterium van eenmalig correct gebruik van een grammaticale structuur (Pienemann), hebben alle deelnemers zowel kennis van de congruentie tussen het adjectief en het substantief (stadium III) als van de congruentie tussen het subject en de persoonsvorm (stadium IV) verworven. Wat het criterium van 50 procent correct gebruik betreft, hebben alle deelnemers de congruentie tussen het adjectief en het substantief en bijna alle (14 van 15) die tussen het substantief en de persoonsvorm correct geproduceerd. Bij het verwervingscriterium van 90 procent correct gebruik hebben alleen drie deelnemers (20 procent) kennis van de congruentie tussen het adjectief en het substantief verworven, terwijl de meerderheid van de studenten ( 86 procent) kennis van de congruentie tussen het subject en de persoonsvorm heeft verworven.

De Processability Theory blijkt dus alleen volledig op te gaan als we uitgaan van een verwervingscriterium van eenmalig correct gebruik dat wel zeer aanvechtbaar is. Dit is ook het criterium dat Pienemann het meest geschikt voor zijn model vindt. In het geval van het tweede verwervingscriterium (50 procent correct gebruik) zit één van de deelnemers [V_20(2)] al in stadium V wat de bijzin betreft hoewel zij voor subject-persoonsvormcongruentie stadium IV nog niet heeft bereikt. Bij het laatste verwervingscriterium (90 procent correct gebruik) zien we duidelijk dat de door Pienemann voorgestelde verwervingsvolgorde A voor B voor C hier niet kan worden toegepast; het wordt eigenlijk B voor A voor C. De meeste deelnemers zitten wat subject-persoonsvormcongruentie betreft al in stadium IV terwijl ze voor adjectief-substantiefcongruentie stadium III nog niet hebben bereikt. En dat is eigenlijk niet zo verrassend omdat grammaticaal gezien de congruentie tussen adjectief en substantief meer complex en ingewikkeld is dan de twee andere geanalyseerde taalverschijnselen.

Uit het onderzoek blijkt dus dat het model van Pienemann niet helemaal opgaat voor het Nederlands als T2. Het zou kunnen betekenen dat het niet genoeg is om binnen het PT model alleen met de aard van de uitwisseling van grammaticale informatie rekening te houden. Wellicht moet men hier ook de complexiteit van de grammaticale structuren van de T2 overwegen. Hoewel er een paar aanzienlijke verschillen zijn wat de aanpak betreft, komen mijn resultaten op veel punten overeen met de resultaten van het onderzoek van Arends (2007: 88). Dergelijke conclusies kunnen het gevolg zijn van verschillende factoren, zoals de invloed van de moedertaal van de deelnemers, hun kennis van andere talen, de hoeveelheid en kwaliteit van de instructies of het testmateriaal. Wat ook belangrijk hier is, zijn alle gegevens in een toetssituatie verzameld die het gebruik van impliciete taalkennis vereist, maar wel anders is dan spontaan taalgebruik. Daarom zal bovenstaand onderzoek nog verder uitgebreid worden. 


\section{Bibliografie}

Alhawary, Mohammad T. (2003): "Processability Theory: Counter-evidence from Arabic second language acquisition data". In: Al-'Arabiyya 36: 107-166.

Arends, Myra (2007): "Verwervingsvolgorde in het Nederlands als tweede taal. Een onderzoek naar de bruikbaarheid van Pienemanns 'Processability'-theorie als verklarend en voorspellend model”. In: Toegepaste Taalwetenschap in Artikelen 77: 79-89.

Baten, Kristof (2011): "Processability Theory and German case acquisition". In: Language Learning 61, 2: 455-505.

Bonilla, Carrie L. (2012): Testing Processability Theory in L2 Spanish: Can readiness or markedness predict development? University of Pittsburgh (Ph.D. thesis), laatst geraadpleegd op: 11.09.2016 (http://d-scholarship.pitt.edu/11611/).

Brown, Roger (1973): A first language: The early stages. Cambridge (MA): Harvard University Press.

Di Biase, Bruno (2007): A Processability approach to the acquisition of Italian as a second language: Theory and Applications. Canberra: The Australian National University (Ph.D. thesis), laatst geraadpleegd op: 11.09.2016 (http://hdl.handle.net/1885/6982).

Di Biase, Bruno \& Kawaguchi, Satomi (2002): "Exploring the typological plausibility of Processability Theory: language development in Italian second language and Japanese second language". In: Second Language Research 18, 3: 274-302.

Dyson, Bronwen (2009): "Processability Theory and the role of morphology in English as a second language development: a longitudinal study". In: Second Language Research 25, 3: 355-376.

Glahn, Esther e.a. (2001): "Processability in Scandinavian second language acquisition". In: Studies in second language acquisition 23: 389-416.

Pienemann, Manfred (1998): Language processing and second language development: Processability Theory, Amsterdam: John Benjamins.

Pienemann, Manfred (2005): “An introduction to Processability Theory”. In: Pienemann, Manfred (ed.): Crosslinguistic aspects of Processability Theory, Amsterdam: John Benjamins, 1-60.

Pienemann, Manfred \& Hakansson, Gisela (1999): "A unified approach towards the development of Swedish as L2: A processability account”. In: Studies in Second Language Acquisition 21: $383-420$.

Mgr. Agnieszka Kucfir $(* 1990)$ is afgestudeerd in neerlandistiek en politologie aan de Universiteit van Wrocław, waar zij momenteel als promovenda werkt aan een proefschrift met de titel Processability Theory in de didactiek van het Nederlands en Pools als T2. Haar interesse gaat vooral uit naar de didactiek van vreemde talen, tweedetaalverwerving en taalfouten.

e-mail: agnieszka.kucfir@uwr.edu.pl 